\title{
El derecho de los Pueblos indígenas al uso del propio idioma en sede judicial
}

\author{
The right of indigenous peoples to use their own \\ language in court
}

\author{
Fernando Kosovsky ${ }^{1}$ \\ Universidad de Buenos Aires, Argentina
}

Revista Derechos en Acción ISSN 2525-1678/ e-ISSN 2525-1686

Año 6/No 19 0toño 2021 (21 marzo a 20 junio), 605-638

DOl: https://doi.org/10.24215/25251678e527

Recibido: 25/01/2021

Aprobado: 15/03/2021

Resumen: La libre determinación de los Pueblos indígenas incluye el derecho a usar su propio idioma en los procedimientos judiciales para garantizar la participación indígena en condiciones de igualdad, tanto a nivel individual como colectivo. Este trabajo explica cómo la normativa constitucional y supralegal garantiza a los Pueblos indígenas el uso de su propio idioma en sede judicial impactando de lleno en los sistemas judiciales argentinos donde se viene implementando el sistema adversarial, cuya nota distintiva es que las controversias se dirimen en audiencias orales, públicas, con inmediación e igualdad, lo que exige respetar y garantizar la interculturalidad. Expertos en antropología aportan aquí sólidos fundamentos para que el estado garantice el derecho al uso de la propia lengua de los pueblos indígenas en sede judicial como derecho individual y colectivo por ello indisociablemente asociado al derecho de participación de los pueblos en asuntos que puedan afectar sus intereses como el control de los actos judiciales, por lo que el intérprete debe ser

\footnotetext{
Abogado por la Universidad de Buenos Aires. Miembro de la Asociación de Abogados de Derecho Indígena (AADI) y del Grupo de Apoyo Jurídico por el Acceso a la Tierra (Gajat). Email: fernando@estudiokos.com.ar.
} 
garantizado por el estado. La casuística exhibe la urgencia de adecuar los sistemas judiciales argentinos para que garanticen efectivamente el respeto de la interculturalidad, dejen atrás la discriminación racial y garanticen la igualdad en un sistema democrático de derecho.

Palabras clave: Pluralismo jurídico, pueblos indígenas, estados, autodeterminación, idiomas, administración de justicia.

Abstract: Indigenous peoples right to self-determination includes the right to use their own language in judicial procedures to guarantee indigenous participation in equal conditions for the individuals and the collective. This work explains how constitutional and international binding law assures the Indigenous Peoples the use of their own language in courts of justice fully impacts in the Argentinean judicial systems where the adversarial litigation is being implemented, being its distinctive note that the controversies are resolved in oral, public hearings with immediacy and equality, which imposes to respect and assure the interculturality. Experts in anthropology contribute here with solid grounds for the state to guarantee indigenous peoples right to use their own of language as an individual and collective right, hence inseparably associated to the right of people to participate in matters which would affect their rights or interests as the control of the judicial acts. Then, the provision of interpretation must be provided by the state. Case studies exhibits the urgency to accommodate Argentinean judicial systems to effectively respect interculturality, leave racial discrimination behind and assure equality in a democratic state of law.

Keywords: Legal pluralism, indigenous peoples, states, self-determination, languages, administration of justice.

\section{Introducción}

La interculturalidad interpela a los sistemas judiciales argentinos.

Una de las derivaciones lógicas del derecho de libre determinación de los Pueblos indígenas es su derecho a usar su propio idioma en los procedimientos judiciales para garantizar la participación indígena en condiciones de igualdad. 
Sin embargo, el atraso en la adecuación de los sistemas judiciales impacta de lleno en los conflictos que tramitan en la República Argentina donde se viene implementando el sistema adversarial, tanto en el proceso penal - e incipientemente en el proceso civil y en el contencioso-administrativo-.

Una de las notas distintivas del nuevo sistema es que las controversias se dirimen en audiencias orales, públicas, con inmediación entre las partes y el Juez imparcial quien procura garantizar la igualdad entre aquellas.

Decimos que la interculturalidad interpela al sistema porque, casi invariablemente, ese Juez pertenece a la cultura judeocristiana, europeo-occidental y hegemónica decidirá conforme a sus pautas, pero ¿Qué sucede cuando las partes pertenecen a otra cultura, entiende el mundo desde otra concepción de la vida -por ejemplo, en el cual la propiedad privada no es el mayor valor social ni el centro de la existencia- y hablan otro idioma?

Ya en la mitad del siglo XX la antropología comenzó a poner en crisis los sistemas monolingüísticos y el derecho internacional fue incorporando como una contribución valiosa el usar el propio idioma de los pueblos indígenas como una libertad fundamental de la persona humana y de los pueblos. En efecto, ese uso está compuesto, inescindiblemente, de un componente individual y de otro colectivo: el derecho subjetivo, el derecho humano fundamental de cada persona indígena a usar su idioma en un procedimiento judicial y del derecho humano fundamental del Pueblo a participar en el mismo procedimiento en condiciones de igualdad.

Lógicamente, ello exige adecuaciones a los sistemas estatales de resolución de conflictos en general y en especial a los sistemas judiciales, adecuaciones que imponen tratados internacionales de derechos humanos y que, según sus principios, deben realizarse con participación y consulta de los mismos pueblos indígenas a través de sus organizaciones representativas. En este ensayo, invito a reflexionar sobre esa adecuación. 
Por ello, tras una breve reseña de normas del derecho positivo que han receptado el derecho de los Pueblos indígenas al uso del propio idioma, compartiré en formato de entrevista (revisada, con notas al pie) el contenido de un Informe de una experta antropóloga, la Dra. Claudia Briones en relación a los fundamentos que la ciencias sociales aportan para argumentar jurídicamente la pertinencia y relevancia del uso del propio idioma de los pueblos indígenas para así poder hacer frente a las resistencias de operadores judiciales. Luego, compartiré voces de la doctrina jurídica especializada.

Para ilustrar las resistencias de los sistemas judiciales a respetar y garantizar el uso del propio idioma de los pueblos indígenas y cómo éstos lo han confrontado, haré referencia a los casos "Pelayes" y "Buenuleo", donde con junto a colegas del GAJAT acompañamos al Pueblo Mapuche litigios en las provincias patagónicas argentinas -Neuquén y Río Negro-, con variantes, rige el sistema adversarial para que se garanticen esos derechos humanos fundamentales.

Por último, a modo de conclusión, aportaré algunos motivos por los que, entiendo, el idioma es una garantía judicial de igualdad y de participación en un sistema democrático de derecho.

\section{Normativa: Recepción del derecho de los Pueblos indígenas al uso del propio idioma}

Como señalé, el uso del propio idioma en sede judicial es un derecho de los Pueblos indígenas reconocido en el derecho positivo constitucional y supralegal, derivado del principio de libre determinación de los pueblos.

En el año 1994, la Constitución incorporó el derecho a la educación intercultural bilingüe como un derecho de los pueblos indígenas. A diferencia de la multiculturalidad donde varias culturas pueden coexistir sin contactos entre sí, la interculturalidad implica contactos, relaciones y equilibrios entre las diversas 
culturas. Es imperioso que el estado adopte medidas positivas para evitar que las culturas hegemónicas sometan, eclipsen y anulen en la práctica a aquellas que fueron históricamente por ellas oprimidas, adoptando el concepto de la igualdad como emancipación.

Estas pautas no son opcionales, sino que son obligaciones internacionales para el estado argentino desde que ratificó mediante la ley 24071 el Convenio 169 OIT que entró en vigencia en el año 2001. La igualdad como principio emancipatorio colectivo e individual está contenida en el artículo 3 establece que "1. Los pueblos indígenas y tribales deberán gozar plenamente de los derechos humanos y libertades fundamentales, sin obstáculos ni discriminaciones. Las disposiciones de este Convenio se aplicarán sin discriminaciones a los hombres y mujeres de esos pueblos...”.

\section{II.1. El derecho al propio idioma y a los intérpretes en los procedimientos judiciales como garantía de igualdad}

Son varios los tratados internacionales de derechos humanos que reconocen a los pueblos indígenas el derecho al uso del propio idioma, en particular, en procedimientos judiciales.

El art. 12 del Convenio 169 de la OIT establece que: "Deberán tomarse medidas para garantizar que los miembros de dichos pueblos puedan comprender y hacerse comprender en procedimientos legales, facilitándoles, si fuere necesario, intérpretes $u$ otros medios eficaces".

El artículo constituye una aplicación práctica de todas las normas que imponen al Estado y a sus funcionarios el reconocimiento y la protección de la cultura de los pueblos indígenas.

Los arts. 75 inc. 17 de la Constitución Nacional y 42 de la Constitución de la Provincia de Río Negro, que reconocen "la preexistencia étnica y cultural" de los pueblos indígenas, y este último, además, a su cultura como “... contributiva de la identidad e idiosincrasia provincial. ...y le garantiza el ejercicio de 
la igualdad en los derechos y deberes. Asegura el disfrute, desarrollo y transmisión de su cultura...".

El art. 27 del Pacto Internacional de Derechos Civiles y Políticos (incorporado a la Constitución Nacional en su art. 75 inc. 22) determina que "En los Estados en que existan minorías étnicas, religiosas o lingüísticas, no se negará a las personas que pertenezcan a dichas minorías el derecho que les corresponde, en común con los demás miembros de su grupo, a tener su propia vida cultural, a profesar y practicar su propia religión y a emplear su propio idioma".

La Convención Internacional sobre la Eliminación de todas las formas de Discriminación Racial asegura "El derecho a la igualdad de tratamiento en los tribunales y todos los demás órganos que administran justicia" (art. 5.a) lo que implica "un servicio de asistencia gratuita de letrados e intérpretes" para las personas pertenecientes a pueblos indígenas y minorías raciales o étnicas. $^{2}$

El Convenio 169 de la O.I.T. también establece que "deberán reconocerse y protegerse los valores y prácticas sociales, culturales, religiosos y espirituales propios de dichos pueblos" (art. 5.a) así como "deberán adoptarse disposiciones para preservar las lenguas indígenas de los pueblos interesados y promover el desarrollo y la práctica de las mismas" (art. 28.3).

El artículo 8 del mismo Convenio establece que:

"1. Al aplicar la legislación nacional a los pueblos interesados deberán tomarse debidamente en consideración sus costumbres o su derecho consuetudinario.

2. Dichos pueblos deberán tener el derecho de conservar sus costumbres e instituciones propias, siempre que estas no sean incompatibles con los derechos fundamentales definidos por el sistema jurídico nacional ni

2 Comité para la Eliminación de la Discriminación Racial (CERD), Recomendación XXXI sobre la prevención de la discriminación racial en la administración y el funcionamiento de la justicia penal. 
con los derechos humanos internacionalmente reconocidos. Siempre que sea necesario, deberán establecerse procedimientos para solucionar los conflictos que puedan surgir en la aplicación de este principio.

3. La aplicación de los párrafos 1 y 2 de este artículo no deberá impedir a los miembros de dichos pueblos ejercer los derechos reconocidos a todos los ciudadanos del país y asumir las obligaciones correspondientes".

La Declaración de las Naciones Unidas sobre los Derechos de los Pueblos Indígenas, en su art. 13 les garantiza el derecho "a revitalizar, utilizar, fomentar... sus idiomas" y obliga a los Estados a garantizarles la protección de ese derecho y también a "asegurar que los pueblos indigenas puedan entender y hacerse entender en las actuaciones políticas, jurídicas y administrativas proporcionando para ello, cuando sea necesario, servicios de interpretación u otros medios adecuados".

Estas normas no agotan el enorme conjunto de disposiciones jurídicas nacionales e internacionales que obligan a respetar la utilización de los idiomas de los pueblos indígenas en los procedimientos judiciales no obstante lo cual son habitualmente ignoradas por los Tribunales argentinos donde está fuertemente arraigada la cultura de la discriminación racial, especialmente en el ámbito de la justicia penal.

Ahora bien: ¿Cuándo son necesarios los servicios de interpretación que el art. 13 de la Declaración impone proporcionar a los estados? ¿Quién y cómo se determina tal necesidad? ¿Qué derechos y garantías están en juego ante la ausencia de un intérprete?

En el caso "CODECI" (2006), el STJ RN desarrolló ampliamente el principio de igualdad real. Desde entonces, la doctrina jurídica especializada ha ampliado el horizonte de los derechos colectivos de los pueblos indígenas, planteando que ese principio debe abarcar las circunstancias y el contexto histórico, postulando al principio de la igualdad como emancipación, el cual dota a los sistemas jurídicos de una mayor capacidad para 
corregir los desajustes de sociedades desiguales en el abordaje de los conflictos.

Este principio, "pro emancipación”, operaría entonces jerarquizando valores sin una pretensión de universalidad, evaluando cada situación en su contexto y aportando criterios objetivos fundados en el análisis de las condiciones históricas que se presenten. (Ramírez, 2018, Pag. 10-11; 21; 55, 62).

La Corte Interamericana de Derechos Humanos, el 3 de abril de 2020 publicó su sentencia del 6 de febrero de ese mismo año (Fondo, Reparaciones y Costas) respecto del Caso "Comunidades Indígenas miembros de la Asociación Lhaka Honhat (Nuestra Tierra) vs. Argentina"3, ordenándole al estado realizar en un plazo máximo de seis meses publicaciones de la Sentencia y su resumen oficial, así como actos de difusión de este último documento, inclusive por emisiones de radio, en lenguas indígenas y en español, con la debida participación indígena en la realización de las comunidades indígenas del caso en las traducciones y difusiones (párrafos 348 y 349 de la sentencia) ${ }^{4}$.

3 Ver detalles en http://www.corteidh.or.cr/docs/casos/articulos/seriec_400_esp.pdf y en https://www.cels.org.ar/web/2020/04/la-corte-interamericana-de-derechos-humanos-condeno-al-estado-argentino-y-fallo-a-favor-de-las-comunidades-indigenas-saltenas/

4 Conviene reproducir aquí dichos textos. Así, el párrafo 348 sostiene: “. . . La Corte estima pertinente ordenar, como lo ha hecho en otros casos, que en el plazo máximo de seis meses a partir de la notificación de la presente Sentencia el Estado: a) publique en un tamaño de letra legible y adecuado la presente Sentencia en su integridad, de modo que esté disponible por un período de al menos un año en el sitio web oficial del INAI y en la página de la Gobernación de Salta, de manera accesible al público desde las respectivas páginas de inicio; b) publique en un tamaño de letra legible y adecuado, en idioma español, el resumen oficial de la Sentencia elaborado por la Corte, por una sola vez, en: i) el Boletín Oficial de la República Argentina, ii) el Boletín oficial de la Provincia de Salta, iii) un diario de circulación provincial en Salta, y iv) un diario de amplia circulación nacional; c) difunda el resumen oficial de la presente Sentencia elaborado por la Corte, en lenguas indígenas y en español, entre la población que habita actualmente los lotes 14 y 55, inclusive cada una de las comunidades víctimas. A fin de cumplir lo último ordenado, el Estado tendrá a su cargo la traducción del resumen oficial de esta Sentencia, pero deberá consensuar con los representantes las lenguas indígenas a las que se traducirá el resumen, y posibilitar que estos verifiquen, antes de su difusión, la corrección de las traducciones. Además, el Estado deberá comunicar a los representantes con una semana de anticipación la realización de las 
La Corte interpretó “... el derecho a la identidad cultural tutela la libertad de las personas, inclusive actuando en forma asociada o comunitaria, a identificarse con una o varias sociedades, comunidades, o grupos sociales, a seguir una forma o estilo de vida vinculado a la cultura a la que pertenece y a participar en el desarrollo de la misma. En ese sentido, el derecho protege los rasgos distintivos que caracterizan a un grupo social, sin que ello implique negar el carácter histórico, dinámico y evolutivo de la cultura" (Par. 240)5.

publicaciones dispuestas en los puntos a) y b) precedentes, así como los actos de difusión dispuestos en el punto c)...". Y el Párrafo 349: “... Asimismo, la Corte considera pertinente, tal como lo ha dispuesto en otros casos330, que el Estado difunda, a través de una emisora radial de amplia cobertura, que alcance a toda la extensión de los lotes fiscales 14 y 15 del Departamento de Rivadavia en la Provincia de Salta, el resumen oficial de la Sentencia, en español y, previo consenso con los representantes, en lenguas de las comunidades indígenas víctimas. La transmisión radial deberá efectuarse cada primer domingo de mes al menos durante cuatro meses, después de las 8:00 hs. y antes de las 22:00 hs. Dos semanas antes de que el Estado realice la primera acción de radiodifusión deberá comunicar por escrito a esta Corte y a los representantes la fecha, horario y emisora en que efectuará tal acto. El Estado deberá cumplir con esta medida dentro del plazo de seis meses contado a partir de la notificación de la presente Sentencia. Argentina deberá comunicar de forma inmediata a esta Corte una vez que haya procedido a realizar cada una de las transmisiones radiales dispuestas en este párrafo y de las publicaciones ordenadas en el párrafo anterior...".

5 Es posible señalar, en el mismo sentido que lo indicado, los conceptos referidos por UNESCO (supra párrs. 237 y 238), el Comité de Derechos Humanos y el Comité DESC. El Comité de Derechos Humanos, respecto al artículo 27 del PIDCP (supra, párr. 234), ha expresado que "no se debe negar a las personas que pertenezcan a [...] minorías el derecho que les corresponde, en común con los demás miembros de su grupo, a tener su propia vida cultural" (Comité de Derechos Humanos. Observación General 23. Derecho de las minorías (artículo 27), párr 5). En la misma línea, el Comité DESC, explicando el artículo 15.1.a. del PIDESC (supra, párr. 234), indicó que "la cultura es un concepto amplio e inclusivo que comprende todas las expresiones de la existencia humana. La expresión 'vida cultural' hace referencia explícita al carácter de la cultura como un proceso vital, histórico, dinámico y evolutivo, que tiene un pasado, un presente y un futuro". Agregó que la "cultura", en el sentido pertinente, abarca "las formas de vida, el lenguaje, la literatura escrita y oral, la música y las canciones, la comunicación no verbal, los sistemas de religión y de creencias, los ritos y las ceremonias, los deportes y juegos, los métodos de producción o la tecnología, el entorno natural y el producido por el ser humano, la comida, el vestido y la vivienda, así como las artes, costumbres y tradiciones, por los cuales individuos, grupos y comunidades expresan su humanidad y el sentido que dan a su existencia, y configuran una visión del mundo que representa su encuentro con las fuerzas externas que afectan a sus vidas". Además, señaló 
Durante las audiencias del caso, hubo intérpretes en lenguas indígenas.

\section{II.2. En la sala de audiencias. El idioma, garantía de participación. Traducción e interpretación}

La traducción y la interpretación facilitan el un proceso de comunicación en un idioma diferente pero no son lo mismo. Es habitual la confusión de abogados, fiscales y jueces, por lo que merece una explicación.

La traducción nos permite comprender, por medio del lenguaje escrito, el mensaje escrito originado en otro idioma. El texto del idioma original es traducido al idioma del receptor por el traductor. Los traductores públicos tienen tal capacidad en el sistema legal argentino. El doblaje y el subtitulado que vemos en las pantallas de cine o tv son traducciones del idioma original.

La interpretación tiene en la simultaneidad uno de sus componentes distintivos; el otro que lo diferencia de la traducción, es la competencia del intérprete: además de conocer el idioma, el intérprete debe tener competencias comunicativas que le permitan comprender la cultura del emisor del mensaje para decodificarlo y ponerlo en términos que el lenguaje de los

\footnotetext{
que "[l]a participación en la vida cultural comprende, en particular, el derecho de toda persona (sola, en asociación con otras o como una comunidad) a [...] identificarse o no con una 0 con varias comunidades, [...y] a ejercer sus propias prácticas culturales"; que "[e]l acceso a la vida cultural comprende, en particular, el derecho de toda persona (sola, en asociación con otras o como una comunidad) a conocer y comprender su propia cultura y la de otros, a través de la educación y la información, y a recibir educación y capacitación de calidad con pleno respeto a su identidad cultural. Toda persona tiene también derecho [... ] a seguir un estilo de vida asociado al uso de bienes culturales y de recursos como la tierra, el agua, la biodiversidad, el lenguaje o instituciones específicas, y a beneficiarse del patrimonio cultural y de las creaciones de otros individuos y comunidades". Agregó que la "contribución a la vida cultural" es una expresión que se refiere al derecho de toda persona a, entre otros aspectos, "participar en el desarrollo de la comunidad a la que pertenece". (Comité DESC. Observación General 21. Derecho de toda persona a participar en la vida cultural (artículo 15, párrafo 1 a), del Pacto Internacional de Derechos Económicos, Sociales y Culturales), párrs. 11. 13 y 15.)
} 
oyentes que no conocen esa cultura puedan comprenderlo en el mismo momento.

En las audiencias públicas de los juicios adversariales, cuya esencia es la inmediación, lógicamente, lo esencial es poder entender lo que se ve, lo que se oye, lo que se siente "en vivo" en la sala de audiencia y por eso el intérprete es la figura insoslayable para que el juez, las partes y el público comprendan a quien usa el idioma no oficial. Si el intérprete es quien permite comprender a quien utiliza el idioma no oficial y viceversa, a quien utiliza el idioma no oficial comprender a los hablantes del idioma oficial, la interpretación es una figura para asegurar igualdad y la participación efectiva en un juicio.

Subtitular una audiencia desnaturaliza el principio de inmediación y discrimina a quienes no hablan el idioma oficial que deben esperar a la traducción para poder acceder a la información que las demás partes ya tuvieron. Si tenemos en cuenta que en el sistema adversarial las oportunidades para objetar una pregunta en un examen a un testigo o a un experto o una impugnación -ej. Reposición- deben ejercerse en el momento, notamos las consecuencias disvaliosas del trato desigual en el derecho de los pueblos indígenas al uso del propio idioma en sede judicial.

Es que, justamente, poder usar su idioma es uno de los elementos esenciales de la identidad de los pueblos. Ello se vincula con el derecho de participación en condiciones de igualdad que reconoce el art. 3 del Convenio 169 de la OIT cuya aplicación general está prevista en art. 6 del Convenio que reconocen el derecho de los pueblos indígenas de participar en cualquier asunto que pueda afectar su interés.

En un trabajo de reciente publicación de la Asociación de Abogadas/os de Derecho Indígena hemos abordado las dificultades de la aplicación judicial del derecho de consulta (Kosovsky, 2020) y los laberintos para que los estados garanticen la participación indígena (Salgado, 2020, P. 107-120) como mecanismo de respeto de la libre determinación de los pueblos y promoción de la interculturalidad. 


\section{II.3. La libre determinación de los pueblos y la interculturalidad}

Los derechos fundamentales de los pueblos indígenas se asientan en los principios de autonomía y libre determinación, que en los términos de la Declaración de las Naciones Unidas sobre los Pueblos Indígenas: "determinan libremente su condición política y persiguen libremente su desarrollo económico, social y cultural" y en su ejercicio "tienen derecho a la autonomía o al autogobierno en las cuestiones relacionadas con sus asuntos internos y locales, así como a disponer de los medios para financiar sus funciones autónomas" (artículos 3 y 4).

Estos principios consagrados en la Constitución y a los tratados de derechos humanos son sistemáticamente desconocidos en las actuaciones estatales frente a los pueblos indígenas en todos los niveles.

Al analizar la aplicación judicial del derecho al idioma veremos cómo el anacrónico paradigma del sometimiento cultural es la normalidad racista que impera en la lógica judicial argentina al momento de interpretar y aplicar las normas jurídicas en materia del idioma y la participación de los pueblos indígenas en los procedimientos judiciales.

Es por ello que la doctrina especializada ${ }^{6}$ propone institucionalizar la participación como una solución imperiosa, en tanto la consulta y la participación son esenciales para garantizar el cumplimiento de todos los derechos de los pueblos indígenas que sólo pueden hacerse efectivos si el Estado establece formas de participación institucional en todas las decisiones que afectan a los pueblos indígenas, en forma permanente y por medio de los organismos representativos de dichos pueblos.

Como apunta Salgado, en general, ni a nivel nacional, ni las legislaturas provinciales, ni los concejos deliberantes municipales han establecido instituciones permanentes y efectivas

\footnotetext{
6 Ver por ejemplo, el mismo Juan Manuel Salgado (2020, P.108-110), donde cita las Observaciones Generales de la Comisión de Expertos de la 0.I.T. referidas a la obligación de consultar del Convenio 169, publicadas en los años 2009 y 201; Comisión de Expertos de la 0.I.T.
} 
de participación, integradas por representantes de los pueblos indígenas. A ello agrego que, salvo experiencias aisladas, tampoco el poder judicial institucionalizó la participación indígena: no hay jueces, fiscales ni defensores indígenas.

\section{II.4. La justificación del intérprete intercultural}

Como abogado defensor, para justificar la pertinencia y relevancia del intérprete intercultural en un caso judicial en el que se había denegado su admisión a un imputado indígena que es una autoridad del Pueblo Mapuche requerí a la Dra. Claudia Briones, que en su calidad de experta ${ }^{7}$ produjera un Informe (Briones, 2020). En su informe, propone un marco teórico general de evaluación general donde estructura dos tipos de problematizaciones y análisis: por un lado, el de las ideologías lingüísticas desde las cuales se debate la posibilidad de expresarse en su propio idioma y, por el otro, el del propio significado y valor asignado por cada pueblo particular a su propia lengua, en este caso, el pueblo mapuche.

Para amenizar su lectura, comparto en formato de entrevista la explicación del informe de Briones cuyo informe reseño pocos conceptos clave para el punto bajo examen, y que constituyen principios básicos de todo encuadre sociocultural del discurso emprendido desde las Ciencias Antropológicas.

\section{Ciencias sociales: fundamentos para argumentar jurídicamente la pertinencia y relevancia del uso del propio idioma de los pueblos indígenas. Entrevista a la Dra. Claudia Briones}

Fernando Kosovsky (FK): ¿Qué son las ideologías lingüísticas?

Claudia Briones (CB): Las ideologías lingüísticas son "sistemas de ideas que articulan nociones del lenguaje, las lenguas, el

\footnotetext{
7 Doctora en antropología (Ph.d) e Investigadora Principal del CONICET en el Instituto de Investigaciones en Diversidad Cultural y Procesos de Cambio (IIDyPCa).
} 
habla y/o la comunicación con formaciones culturales, políticas y/o sociales específicas (...) que se producen y reproducen en el ámbito material de las prácticas lingüísticas y metalingüísticas" (Del Valle 2007, P. 20). En otras palabras, preconceptos sobre lo que las lenguas son y hacen, o permiten hacer.

FK: ¿Qué es el "giro discursivo?

CB: Ferdinand de Saussure (1965), hace evidentes las complejas relaciones entre lengua o langue (sistema de signos) y habla o parole (manifestación particular de ese sistema en el acto de comunicación). Pero es sobre todo con el llamado "giro discursivo" y el predominio de los enfoques pragmáticos en las Ciencias Sociales que se pasa de un paradigma que ponía las ideas y la introspección racional en el centro de la observación certera del mundo, a otro que prioriza la observación y el análisis de los discursos en sus contextos (Duranti, 2000).

FK: ¿Qué funciones prácticas cumple el lenguaje?

CB: Fairclough (1992) indica que toda enunciación debe verse simultáneamente como una práctica textual, una práctica discursiva y una práctica social.

FK: ¿Cuáles son las imposiciones lingüísticas?

CB: Hay que prestar atención a qué y cómo se dice lo que se dice (texto); a cómo la enunciación se da en una situación particular que la afecta es afectada por ella (discurso); y que todo acto de habla es una práctica social que queda enmarcada por los contextos socioculturales y sociopolíticos más amplios, atravesados por ideologías lingüísticas hegemónicas que jerarquizan las distintas lenguas en uso, imponen idiomas nacionales a todos los habitantes por igual, establecen varas asimétricas para juzgar y valorar el decir y lo dicho de diversos hablantes. Por ello, así como en toda sociedad existen desigualdades sociales que violentan el margen de acción disponible para quienes quedan en posiciones subalternas, ese mismo violentamiento se expresa y recrea a través de las imposiciones lingüisticas 
FK: ¿Cómo opera (expresa y reproduce) el discurso las relaciones de poder?

CB: Teun Van Dijk (2001, 2009) argumenta que es también en el discurso y los intercambios discursivos que las relaciones de poder se expresan y reproducen (2009). También, que es en y a través del discurso que las élites políticas, burocráticas, corporativas, mediáticas, educativas controlan las dimensiones y decisiones más cruciales de la vida cotidiana de las minorías, y materializan el racismo (2001).

FK: ¿Cuáles son las funciones del discurso?

CB: Norman Fairclough (op. cit.) destaca a su vez que el uso del lenguaje, como práctica textual, discursiva y social, lejos está de tener una función instrumental de transmisión de información. Por el contrario, todo acto de habla cumple simultáneamente tres funciones. A saber, una función relacional, una identitaria y otra representacional. Si la función relacional construye las relaciones sociales entre hablantes como simétricas o asimétricas, como hostiles o íntimas, la función identitaria expresa pertenencias y opera las distinciones y vínculos esperables entre propios y ajenos. La función representacional, por su parte, expresa cosmovisiones o visiones del mundo.

FK: ¿Cuál es la diferencia entre competencia lingüística y competencia comunicativa?

CB: Cuando el uso de dos lenguas se pone en relación, resulta imprescindible reconocer la diferencia entre competencia lingüística y competencia comunicativa. La competencia lingüística es la habilidad de usar y manipular las reglas fijas de una lengua y se establece desde parámetros de valoración en torno a la gramaticalidad de las enunciaciones. Por el contrario, la competencia comunicativa es la habilidad de usar el idioma dentro de la comunicación, esto es, expresar una variedad de palabras de manera apropiada para cada situación. Se puede entonces tener cierta competencia lingüística en una segunda lengua, pero no 
la competencia comunicativa para participar de modo acorde a la forma de interacción social propuesta (Gumperz 1972; Hymes 1971 y 1972). Esto es, la competencia comunicativa está siempre socioculturalmente condicionada y es lo que incide en las posibilidades de concretar una performance (Lyons 1996) o escenificación social que para la audiencia resulte apropiada y para quien la realiza resulte cómoda y no violentante.

Si la diferencia entre competencia lingüística y competencia comunicativa que habilita distintos tipos de performances en una misma situación social deviene criterio clave al momento de crear y valorar condiciones de equidad comunicativa, esos conceptos se complejizan en contextos que ponen en juego y uso más de una lengua, y complejizan a su vez la propia definición de bilingüismo, que no puede considerarse sin más como competencia lingüística equivalente en dos lenguas. Esto es, se puede poder hablar ambas, pero con muy distinto grado de competencia comunicativa y desde muy distintos repertorios lingüísticos, lo que a menudo pone a quien es forzado a usar su segunda lengua en situación de desventaja social. Por eso Blommaert (2010) habla de "repertorios truncados", para llamar la atención a que en contextos multilingües los recursos con que cuenta quien no habla su lengua materna tenderán a ser considerados y/o vividos siempre como incompletos, disímiles, fragmentados, lo que potencia situaciones de discriminación, a la par de poner en inferioridad enunciativa al hablante. Blommaert y Backus (2011) por su parte plantean que la justa apreciación de los repertorios disponibles para cada cual sólo puede darse en función de las biografías de los hablantes, pues se van componiendo a partir de las diferentes experiencias de vida, lugares de procedencia, etc. Por eso Sichra (2005) propone hablar de "bilingüismo situado", porque el uso de dos lenguas nunca puede considerarse una capacidad homogéneamente distribuida, sino que debe ser enmarcada en la situación social vivida y construida por hablantes cuyos usos lingüísticos quedan siempre definidos por y desde sus actitudes e identidad. 
FK: ¿La oficina judicial de Bariloche denegó la solicitud de un intérprete en Mapuzungun porque los imputados hablan y entienden el castellano? ¿Esa decisión, respetó el derecho a la libertad de expresión? ¿Por qué?

CB: A partir de estas nociones, Gandulfo (2020) propone no hablar de bilingüismo sino pensar los desempeños en términos de un "continuum lingüístico" entre dos lenguas, con posibilidades de muy dispar competencia comunicativa en ambas. Por tanto, no se puede juzgar de modo simple quién es o no es "bilingüe", sino anticipar y habilitar dispares competencias comunicativas desde un determinado "continuum lingüístico" y habilitar su uso para no vulnerar el derecho de expresión.

Así, cuando estas materialidades y circunstancias de las prácticas discursivas no son ni reconocidas ni debidamente evaluadas desde una ideología lingüística esencializante, los contextos de convivencia devienen diglósicos ${ }^{8}$.

Por ello, los derechos lingüísticos -que son tanto individuales como colectivos- apuntan a proteger no solo el derecho humano a hablar sin condicionamientos de contenido ni de forma e instrumento de expresión (uso de lengua específica), sino también las convivencias basadas en la coexistencia real de la diversidad lingüística (Hamel 1995).

FK: ¿Qué estudios hay sobre el idioma Mapuche?

CB: El idioma mapuche tiene un registro y estudio intenso desde los primeros momentos de la conquista (Salas 2003). En paralelo a su gramática, hay disponibles numerosas antologías. Sin embargo, no es desde el punto de la lengua como sistema

8 Se define como diglósica toda situación en la que en una comunidad de hablantes coexisten dos o más lenguas o variantes de lengua de las cuales una goza de mayor prestigio social que la/s otra/s y, por imponerse, acaba limitando el uso de la propia lengua a ámbitos o circunstancias acotados. Por eso se entiende que la diglosia conforma una censura al derecho de libre expresión. Aun así y como detalla Fishman (1967), debe entenderse que las relaciones del bilinguismo con la diglosia son complejas. 
de signos sino desde el habla como práctica que produce efectos que hay distintas cuestiones a examinar.

Tanto las primeras gramáticas y comentarios de período colonial temprano sobre el idioma mapuche de las que disponemos, como variadas etnografías del habla contemporáneas, destacan la importancia y alta valoración asignada a la buena oratoria en mapunzugun. Esa oratoria a su vez se diversifica desde una teoría mapuche del discurso que reconoce claramente muy distintos géneros discursivos apropiados para distintas situaciones sociales (chalitun, pentukuwün, ngütram, epew, koyautun, tayil, konawül, etc.). Cada uno de estos géneros define las competencias requeridas de las performances que habilita, crea relación social entre hablantes y audiencias, tiene sus propios criterios de evaluación, de toma de turnos, o estándares respecto del valor de verdad de lo dicho y de la relación del enunciador con ello.

FK: ¿Qué son los especialistas?

CB: Los especialistas son conocedores en aspectos variados de la cultura que recurren a su vez a esos diversos géneros discursivos desde particularidades que hacen a su rol. Así como un/a machi (consejero/a que asegura el bienestar físico, mental y espiritual de las personas) debe cultivar géneros discursivos no disponibles para otros hablantes, un/a logko o jefe político-espiritual tiene que intervenir discursivamente en diferentes ocasiones clave de la vida social, pues es eso lo que materializa y se demanda de su rol de líder. Está asimismo el ngenpin, especialista en "guardar la palabra" o la memoria, para compartirla en los momentos adecuados con distintas audiencias, siendo quien asesora sobre filosofía, espiritualidad, ciencia y sabiduría ancestral y el responsable de proyectar y proteger dichos conocimientos, como quien relata a los niños/as distintas historias que los introducen a los conocimientos propios.

Muchos de esos especialistas precisan de intérpretes, cuya función no es traducir, sino adecuar el repertorio lingüístico 
que solo maneja el especialista a las audiencias propias de la situación social en que ese especialista se desempeña. Esto no es solo propio de las prácticas de machitun (todo/a machi tiene su propio zungumachife), sino que ha sido extensamente documentado en las ocasiones de celebrar tratados coloniales y republicanos, donde todo logko -aun sabiendo hablar castellano- iba acompañado de su "lenguaraz".

En todo caso, la necesidad e importancia de los intérpretes sólo se comprenden a la luz de la filosofía mapuche del lenguaje en dos aspectos clave.

Primero, el decir correcto, küme chi zugnu o buena palabra, no solo comunica, sino que actualiza o hace presentes los distintos "vivientes" mencionados en y por el discurso. Como una vez nos dijo un kimche (maestro o sabio) respecto de por qué había siempre que decir de quién se había aprendido o escuchado algo: "yo los cito a ellos, porque cuando uno conversa, llegan ellos, porque los siente en la espalda". En este caso, se refería al püllü o espíritu de sus mayores de quienes -según explicó- recibió todo su kimün o sabiduría aunque eran analfabetos.

Segundo, los distintos especialistas deben esforzarse por aprender su rol, pero no lo eligen, les viene dado por destino. Así, lo que cada persona es proviene de su küpalme. En este sentido, el mismo kimche nos explicaba que él podría hacer de ngillatufe (oficiante de la rogativa), por su buen mapunzungun y porque, habiendo asistido a muchas, conoce el qué y cómo hacer. Sin embargo, él no está destinado a ser ngillatufe, por lo que sus enunciaciones, su decir, nunca podrían producir los mismos efectos que el mapunzungun produce cuando es usado por quien nació destinado a ser ngillatufe.

En otras palabras, los intérpretes son necesarios porque comunican a la audiencia lo que el especialista quiere transmitirle, pero su manera de expresarse necesariamente debe transformar lo que sólo el especialista puede "hacer" al decir, en términos de hacer presentes los distintos vivientes invocados. 
FK: ¿Qué rol tiene un especialista en Mapuzungun en un proceso judicial?

CB: Sin duda, las declaraciones en el marco de acciones procesales son un ámbito diferente y relativamente novedoso para los hablantes de mapunzungun, pues no solo incorporan interlocutores no mapuche --como ocurría con los contextos de firma de tratados (Briones y Carrasco 2000)-, sino que se desarrollan en un contexto social y en medio de prácticas discursivas completamente ajenas. En verdad, el discurso y la ritualidad jurídicas son ajenos para la mayor parte de la población. Sin embargo, como en toda situación social, la palabra no circula solamente desde y hacia los operadores jurídicos, pues puede haber en el auditorio otros mapuche a quienes los declarantes inevitablemente se están dirigiendo y se quieran dirigir ${ }^{9} .{ }^{10}$ En estos casos, es probable que el uso del mapunzungun no solo busque introducir en una situación ajena un mínimo de las pautas de etiqueta mapuche usando los géneros discursivos apropiados (como el chalitun o saludo de presentación de cada persona donde se explicita su küpalme y tuwün), sino también testimoniar de modo de que sus acciones sean públicas y entendibles para ese auditorio que comparte el mismo idioma y etiqueta. Así, el rol de intérpretes avezados no sólo operaría en la dirección de expresar de maneras entendibles para el declarante las prácticas discursivas de los operadores jurídicos, sino también en la de comunicar de maneras que puedan hacerse públicas y accesibles para distintas audiencias lo que el declarante "hace" con su decir.

9 Desde la perspectiva mapuche, una acción individual puede influir en el bienestar del conjunto y un yerro colectivo puede enfermar a una persona particular. En este sentido, para una persona mapuche que llega a juicio puede resultar igualmente importante aclarar su accionar ante el Tribunal, como ante quienes forman parte de su familia, comunidad y Pueblo. Por ello, la mayor parte de las instancias que el Poder Judicial considera afectando a personas particulares, para el testimoniante mapuche se ven como involucrando a colectivos más vastos, ante los cuales debe también poder expresar y dejar clara su declaración. 
FK: ¿Qué implicancias tiene la ausencia de intérprete en Mapuzungun en una audiencia judicial en la que interviene un Mapuche en general y un Lonko en particular?

CB: La filosofía mapuche del lenguaje atribuye al mapunzungun como "idioma de los vivientes de la tierra" capacidades que una ideología lingüística objetivista no advierte ni toma en consideración. Más allá del poder diferencial de la palabra de las distintas autoridades ancestrales del pueblo mapuche ${ }^{10}$, es previsible que distintos hablantes -comprendan y/o manejen el castellano con distintas competencias comunicativas- busquen expresar a través del idioma propio una pertenencia (función identitaria de las prácticas discursivas), cierta manera de concebir y proponer relaciones sociales (función relacional), y maneras de ver el mundo y las cosas (función representacional) para distintas audiencias a la vez.

FK: ¿Cómo afectaría la imposición de un único código lingüístico a un imputado Mapuche?

CB: En estos casos, la imposición de un único código lingüístico no afecta simplemente las posibilidades de comprensión de lo que está ocurriendo, sino las de expresar la identidad propia, las maneras de concebir y buscar encauzar las relaciones e interacciones sociales según la etiqueta mapuche, así como ciertas conceptualizaciones que no tienen una traducción lineal. Es en este sentido que la imposición de un único idioma opera una violencia epistémica (Castro Gómez, 2000) que en Ciencias Sociales queda definida como epistemicidio (Souza Santos, 2010).

Aunque no todas las diferencias culturales pueden encontrar equivalencias, en una situación que reconozca y respete su carácter intercultural, corresponde que las mismas puedan

\footnotetext{
10 Un logko, machi o genpin, tienen un rol y funciones asociados al conocimiento especialmente profundo de la filosofía mapuche, refieren a vínculos con las fuerzas del territorio y los espíritus de los ancestros, tiene capacidad de levantar ceremonias y a la guía espiritual y/o política de las personas y familias mapuche.
} 
al menos comunicarse libremente, de modo de no censurar la libertad de expresión ni neutralizar la diversidad lingüística. Los intérpretes avezados son quienes sabrían y podrían maniobrar entre los bordes culturales, epistemológicos y ontológicos que son propios de esas situaciones.

\section{Doctrina jurídica: opiniones con relación al uso del propio idioma en sede judicial}

Manuel Moreira (2009, pag. 200) sostiene: “... es prácticamente desconocido por los jueces con competencia penal que continúan aferrados a los Códigos de Procedimientos locales, donde el indígena no aparece y solamente en algunos casos se tiene en cuenta el idioma y la necesidad de un intérprete". Los pueblos indígenas son una de las excepciones a la regla del que los actos procesales deben ser cumplidos en el idioma oficial bajo pena de nulidad.

Los indígenas poseen "... el derecho de que se hable en su idioma, entienda o no entienda el idioma oficial". Es el caso del sujeto procesal cuyo idioma ha sido declarado promovido por el estado y en consecuencia adquiere un derecho diferente de aquel que revela un impedimento para hablar o hacerse entender. Así lo impone el art. 28.3 del Convenio 169 de la OIT. Su uso no es obligatorio, sino que se deja a voluntad de sus usuarios. En cambio, el Estado tiene la obligación de garantizar a sus hablantes el uso del mismo, comunicarse con ellos en ese idioma, dado su tipo promocional y fomentar su conocimiento, divulgación y uso. Tal es la interpretación conjunta del art.75.17 $\mathrm{CN} 2^{\circ}$ párrafo en el que enlaza la garantía del respeto a la educación bilingüe e intercultural, complementariamente a lo que ya sostenía la ley 23.302 arts.- 14-16 y la ley federal de educación 24195-93. "No existe ninguna duda sobre el estatus de las lenguas indígenas en nuestro país y sin embargo en los tribunales, cuando un indígena es juzgado o participa de un proceso como testigo, se usa el intérprete como si fuese el hablante de un idioma extranjero "respetado" o "permitido". 
"Así, se ignoran claras disposiciones legales, que concurren dentro de una interpretación sistemática de la ley procesal y que hacen al debido proceso y a la igualdad ante la ley". Ello es “... fuente de una desigualdad notoria, al colocar al indígena en una posición asimétrica, privándolo de un derecho reconocido por normas supralegales, como lo establece, expresamente el art. 12 del Convenio 169 de la OIT (Moreira 2009, P. 202-3).

Esta posición es compartida por Hualpa (2014, pp. 209 y ss.) al describir el impacto de la reforma constitucional de 1994 y del Convenio 169 de la OIT, y en especial, en materia penal, explica que "El derecho del imputado a tener un intérprete para expresarse en el idioma materno surge de instrumentos de derechos humanos como la Convención Americana de Derechos Humanos (art. 8.2.a) el Pacto de Derechos Civiles y Políticos (art. 14.3.a y f.-). La última frase del art. 12 del Convenio 169 de la OIT, ...en el mismo sentido se expresa el art. 13.2 de la Declaración de Naciones Unidas sobre los Derechos de los Pueblos Indígenas".

Es importante destacar que aunque la previsión de intérpretes para toda persona que imputada de un delito, la garantía resulta más intensa para los miembros de los pueblos indígenas, ya que en este caso no se encuentra limitado por la condición de ignorar el idioma oficial ya que como bien explican Gomiz y Salgado: “... la cláusula constitucional y el principio de no discriminación implican que los miembros de los pueblos indígenas deben poder expresarse con la misma soltura al hablar con que se manifiestan los ciudadanos no indígenas..." (Gomiz y Salgado, 2010)

María Micaela Gomiz y Juan Manuel Salgado (2010) en su comentario al Convenio 169 de la OIT también apuntan, sobre el art. 28 que el apartado 3 impone una obligación fuerte sobre los estados, que deberán adoptar medidas apropiadas para proteger los lenguajes indígenas, a los que el Convenio 169 les reconoce un valor propio como consecuencia de la positiva consideración de la diversidad lingüística. Esta protección 
debe ser realizada promoviendo su desarrollo y práctica. Entre las medidas necesarias se encuentra el reconocimiento de los lenguajes indígenas como idiomas oficiales, o al menos el derecho de los pueblos indígenas a que sus comunicaciones con el Estado se realicen en sus idiomas (artículos 4 y 5 del Convenio), aun cuando tengan cierto dominio del lenguaje oficial.

\section{Estado del debate en sede judicial}

Como antecedentes previos a la incorporación del sistema adversarial, me remito a los casos citados por Eduardo Hualpa en el Capitulo X "Derechos en relación al sistema penal”, Pag. 248 y ss de la citada obra, en el apartado A. Derecho al intérprete, en los que cita la Causa "Díaz" (STJ Chaco, "Díaz, Roberto s/ Homicidio" (25/11/99); el caso "Torales Vega" del STJ Formosa, "Torales Vega, Hilario, Torrent Carlos Ovidio s/ Homicidio Vega, Lucio s/ Homicidio gdo. Tentativa" (24/11/05) que analiza en el punto X.C.2 de su libro donde la Cámara Segunda en lo Criminal de Formosa designó a un intérprete Qom para que se expresen los imputados, luego consideró que el mismo había incurrido en falso testimonio, lo que motivó que el Ministro del Superior Tribunal de Justicia Ariel Coll, considerara que el Tribunal dudaba de la asistencia del acusado, lo que por la grave y directa violación a la defensa en juicio determinaba la declaración de nulidad aún de oficio, de la condena dictada. El voto, que conformó la mayoría por fundamentos propios, da cuenta del valor de asignado por el ordenamiento jurídico a la designación y labor de los intérpretes en causas en las que los imputados son miembros de un pueblo indígena. Recuerda además la sentencia del Juzgado Correccional de Zapala, "Añiñil, Pablo y otros s/ Usurpación en concurso ideal con desobediencia a una orden judicial y s/ impedimento de un acto funcional", (providencia de fecha 26/10/2009) una jueza negó a procesados indígenas el derecho a expresarse en mapuche ya que no se trataba del "idioma nacional. La negativa de designación fue considerada por la defensa como un acto de discriminación 
racial. La repercusión mediática de la negativa motivó a la Cámara de Apelaciones a aceptar la recusación, no por admitir la alegación de discriminación sino por entender que el nivel público de confrontación podía poner en duda la apariencia de imparcialidad.

\section{V.1. El caso "Pelayes"}

En el caso "Palayes", tres personas integrantes del Pueblo Mapuche habían sido acusadas por hechos ocurridos en diciembre de 2012 en Zapala, Neuquén, donde se dictó una orden judicial para que integrantes de la comunidad Winkul Nehuen no obstaculizaran el paso en el paraje Portezuelo a la empresa petrolera Apache. Según la acusación, la oficial de justicia, Pelayes, habría sido agredida al momento de la notificación.

El Fiscal y la querella solicitaron audiencia para formular cargos a los imputados que encuadró como tentativa de homicidio y daños agravados en perjuicio de la víctima.

La defensa planteó que, si bien los imputados entienden el castellano -idioma oficial- solicitaron un intérprete en mapuzugún -la lengua mapuche- como parte de la garantía de igualdad en el proceso, del derecho a la identidad y en reconocimiento de la preexistencia de las comunidades originarias e indígenas en el país para poder así controlar los actos del proceso.

La petición, denegada por el juez de garantías, fue impugnada por la defensa de los imputados Mapuche que el Tribunal de Impugnación de la Provincia del Neuquén ${ }^{11}$, por mayoría, hizo lugar a la misma.

En este fallo el Tribunal reivindicó la diversidad cultural, dando un alcance amplio a la cultura. Receptó el planteo de la defensa según el cual la comprensión del idioma de un pueblo

11 Causa "Soae Carol, Velásquez Marileo Martín, Rain Mauricio S/Lesiones graves y Daño", Legajo: (10450/2014), Zapala, sentencia del 18 de junio de 2014. Mario Rodríguez Gómez, Alfredo Elosu Larumbe y Mabel Folone, por mayoría. 
originario no es por una cuestión de entendimiento del proceso, sino ya como un derecho a la identidad y al control de los actos por parte de todas las comunidades originarias. se programa una nueva audiencia donde los cargos a los imputados los leerá también un intérprete mapuzugún.

El Tribunal de Impugnación de Neuquén hizo lugar al planteo de la defensa y resolvió que debía volver a realizarse la audiencia impugnada con un intérprete en Mapuzungun.

La defensa requirió que la provincia de Neuquén llame a concurso de un intérprete de mapuzugún, así como llama a jueces y fiscales, poniendo en debate la lógica del concurso pues “... ¿desde qué lugar el Estado te puede acreditar como intérprete? ...las propias comunidades podrían definir quién puede usar el idioma de forma tal que interprete correctamente: se podría hacer convocar a la Confederación Mapuce o a las comunidades originarias de Neuquén para que aporten ideas de cómo crear el cargo o crear una lista de posibles intérpretes con aval de las comunidades", dijo entonces el defensor, Darío Kosovsky. ${ }^{12}$

Lo que diferencia el fallo de otros que incluyen intérpretes es que se establece desde el Poder Judicial un valor especial a la palabra: se reconoce al lenguaje como algo inherente a la identidad.

En audiencias anteriores, desde el TSJ neuquino habían avalado contar con un intérprete, pero planteaban que como era complejo conseguirlo se imponía la carga a la defensa. A partir de este fallo el intérprete no solo se postula como un derecho, sino que también debe ser garantizado por la Justicia.

Es el primer antecedente donde los imputados comprenden perfecto el idioma y, al mismo tiempo que entiendan los fiscales y jueces, lo podrán ver todas las comunidades mapuches que quieran, ya que desde el nuevo Código procesal penal las audiencias no tienen registro escrito, sino que son filmadas.

\footnotetext{
12 Ver en http://www.archivoinfojus.gob.ar/provinciales/obligan-a-incorporar-en-un-juicioa-un-interprete-en-lengua-mapuche-2017.html
} 
Al no existir en los registros de intérpretes del Poder Judicial, la búsqueda de una solución para la designación de un intérprete se la impuso a la Oficina Judicial y al Superior Tribunal de Justicia de la Provincia, órganos de administración y de gobernanza del sistema judicial. La defensa cooperó informando cuales son las instituciones indígenas legalmente reconocidas en la provincia, en el caso, la Confederación Mapuce del Neuquén, para que puedan dar participación y consultar qué por intérpretes idóneos para el caso.

La importancia del caso "Palayes" es la valorización del derecho cultural al uso del propio idioma como una de las garantías que integra el debido proceso legal y por lo tanto le corresponde al estado asegurar su cumplimiento.

Con el mismo criterio, también en el caso "Palayes", la defensa solicitó y obtuvo la intervención del intérprete en Mapuzungun por primera vez en la historia del sistema penal argentino un jurado intercultural con participación equitativa del Pueblo Mapuche (Harfuch, Bilinski, y Ortiz, 2014)

Como introdujeron las defensas, en el proceso penal adversarial es una condición del principio constitucional de interculturalidad que los imputados que hablaban en idioma mapuzungun puedan hacerlo libremente y que sus expresiones sean simultáneamente comprendidas por el Juez, por las partes y por el público, el cual controla que durante la audiencia se respeten las demás garantías individuales.

\section{V.2. El caso "Buenuleo"}

En el caso "Buenuleo"13, el 16 de septiembre de 2019 el Fiscal de S.C. de Bariloche imputó a varios integrantes de la Comunidad Mapuche Buenuleo y el Lonko ("cabeza", autoridad tradicional) Mapuche de la comunidad Pillan Mahuiza, Mauro Millán, por usurpación solicitando su desalojo cautelar al Juez

13 "Buenuleo Ramiro y otros (Comunidad Buenuleo) s/Usurpación", Legajo: MPF-BA04875-2019 
de Garantía Sergio Pichetto quien tuvo por formulados los cargos y ordenó el desalojo cautelar.

La defensa de los Buenuleo impugnó el desalojo y planteó la incompetencia de la justicia provincial. La impugnación ordinaria fue rechazada por el Juez Marcos Burgos y la defensa interpuso revisión extraordinaria contra la orden de desalojo ante el Tribunal de impugnación que admitió el recurso y convocó a una audiencia para los fundamentos. El caso quedó suspendido entre Marzo y Julio de 2020 por la pandemia Covid-19. Reanudados los plazos y dirimida la cuestión de competencia a favor de la justicia provincial, el Tribunal de Impugnación convocó a una audiencia de conciliación en los términos del art. 14 del CPP RN (ley 5020) para intentar la resolución alternativa del conflicto.

En la audiencia, la defensa del Lonko Millán pidió la intervención de un intérprete en Mapuzungun, fundado en la garantía de publicidad e invocando el estándar del caso "Pelayes". La defensa de los miembros de la Comunidad imputados se adhirió al planteo.

La audiencia se realizó el 8 de septiembre de 2020 en el marco de la pandemia Covid-19 por la aplicación Zoom. Aplicando una acordada del STJ, el Tribunal limitó la participación únicamente a las partes y a sus abogados, impidiendo la participación del público, el cual fue desconectado por la oficina judicial. El Fiscal se opuso al intérprete en Mapuzungun, aduciendo que los imputados comprendían el idioma oficial, ignorando el planteo de control de publicidad del proceso penal, posición compartida por el Tribunal ${ }^{14}$ por unanimidad que desestimó la solicitud de la defensa.

La defensa impugnó lo que consideró una actuación procesal defectuosa lesiva del derecho a ser oído en condiciones

\footnotetext{
14 Sentencia del 9 de octubre de 2020 del Tribunal de Impugnación de la provincia de Río Negro integrado por María Rita Custet Llambí, Adrián Fernando Zimmermann y Carlos Mohamed Mussi.
} 
de igualdad por la negativa a garantizar el intérprete para los Mapuche. Se agravió por el impedimento de la participación popular en el control de los actos judiciales -publicidad- en el caso cuyos aspectos colectivos del conflicto eran medulares para la teoría del caso de la defensa consistente en que los imputados ejercen la posesión comunitaria indígena mediante la ocupación tradicional del territorio Mapuche. Por ende, resulta de cabal importancia la participación como público del Pueblo Mapuche para el control de los actos judiciales y la comprensión de los alcances de la cuestión debatida en el conflicto.

Sin embargo, el Tribunal desconoció el derecho al uso del idioma Mapuche y del control del Pueblo Mapuche en su propio idioma mediante el intérprete, aduciendo que los imputados entendían el idioma oficial.

El 9-10-2020 el Tribunal de impugnación rechazó el recurso extraordinario contra dicha sentencia.

La presidente del Tribunal, Dra. Rita Custet Llambí, dijo que consideraba que la participación y la publicidad podían satisfacerla accediendo a la copia de la audiencia y colocándole subtítulos. El Juez Adrián Zimmerman en su voto completó la argumentación dislógica -pero, además, racialmente ofensiva-, en los siguientes términos:

"Es muy importante en el nuevo sistema adversarial la oralidad y de allí la interpretación de lo que sucede durante el acto procesal, lo que efectivamente sucedió con los imputados a quienes se les preguntó inclusive si deseaban expresarse y, salvo Millán, se abstuvieron. Fácil es advertir en las audiencias el desenvolvimiento, conductas y formas de comunicación y expresarse de los imputados quienes, más allá de la cultura originaria, comprendieron acabadamente todo lo sucedido en plena situación de igualdad a cualquier otro ciudadano del país, y las eventuales cuestiones jurídicas sobre las que tuvieran dudas pudieron consultarlas con sus asesores jurídicos, como cualquier otro imputado. Esta es la finalidad cumplida prevista en Convenio 169 OIT (ver 
art. 11 in fine, entre otros). ... "Las Defensas pretenden un distinto y preferencial trato por el solo hecho de pertenecer a una comunidad originaria, situación que está vedada por la Constitución Nacional (art. 16) y no responde a los fines del citado Convenio, y pretender un intérprete cuando de las constancias del legajo y la realidad demuestran que es una petición por la petición misma sin resultado efectivo por la interculturalidad mostrada por los encartados...la petición de intérprete es un capricho y una chicana".

Los Jueces del Tribunal fueron interpelados por la defensa sin poder responder razonablemente estos interrogantes: "Ustedes, cuando hacen sus alocuciones, tomas sus decisiones, las pueden explicar en la cultura o en mapuzugún durante la audiencia? Evidentemente no pueden. Si hay alguien que violenta una garantía en esta audiencia. ¿Cómo podría alguien en el público entenderlo si no hay alguien en su cultura que se lo está permitiendo comprender? ¿Y si tengo que interponer una reposición -que el Código me obliga a plantearla en la audiencia- no tengo manera de validarlo culturalmente porque mi parte, tal vez, no pueda decirme que me están violando mi derecho, porque no lo está entendiendo mediante su cultura y yo pierdo, de esa manera, el derecho realizar una defensa efectiva, y en condiciones de igualdad que establece el art. 16 de la Constitución Argentina, la Constitución de Río Negro, C. 169 OIT y la UNDRIP, así como medidas impuestas por los arts. 2, 8 y $25 \mathrm{CADH}$ que garantiza la efectividad de las garantías - cuya jerarquía constitucional establece el art. 75 inc. 22 CN- según lo dispuso la Corte Interamericana de Derechos Humanos al aplicar la Convención Americana de Derechos Humanos en el "Caso Comunidad Indígena Sawhoyamaxa vs. Paraguay", Sentencia de 29 de marzo de 2006, (Fondo, Reparaciones y Costas) (párrafos 110-112) 15 .

15 “... 110.El artículo 2 de la Convención impone a los Estados Partes la obligación general de adecuar su derecho interno a las normas de la propia Convención, para garantizar así los 
En cuanto a la compatibilidad de tener un intérprete en mapuzugún en la audiencia esta defensa interrogó sin lograr una respuesta razonable acerca de: ¿Cuál es la lesión o el agravio para el fiscal o la querella que los imputados y la defensa entiendan en su propia cultura entiendan en su propia lengua?

\section{V.3. El logro del intérprete}

Con nuevos elementos investigativos (la carpeta técnica del INAI del art. 3 de la ley 26.160 y prorrogada por última vez por la Ley 27.400) que demostraban su ocupación tradicional indígena sobre el lugar en el que les imputaban usurpación, Comunidad solicitó una audiencia de sobreseimiento, requiriendo que en ella intervenga un intérprete en Mapuzungun para poder hacer uso de su idioma.

Al fijar la audiencia, la Directora de la Oficina judicial de Bariloche sostuvo "Respecto a la solicitud de un intérprete en el idioma Mapuzungun, se le hace saber que las personas aquí imputadas, que pertenecen a una comunidad mapuche, conocen la lengua castellana en la cual se llevará adelante la audiencia y no se encuentra afectado de ninguna manera el derecho de defensa".

Contra dicha resolución, la defensa del Lonko y de los demás imputados requirió audiencia de control de la actividad procesal defectuosa de la Oficina Judicial por su extralimitación ilegal en el dictado de una resolución administrativa decidiendo

derechos consagrados en ésta. Las disposiciones de derecho interno que sirvan a este fin han de ser efectivas (principio del effet utile), lo que significa que el Estado debe adoptar todas las medidas necesarias para que lo establecido en la Convención sea realmente cumplido. 111. En el presente caso, el Paraguay no ha adoptado las medidas adecuadas de derecho interno necesarias para asegurar un procedimiento efectivo que dé una solución definitiva a la reclamación planteada por los miembros de la Comunidad Sawhoyamaxa, en los términos de los párrafos anteriores. 112. Por todo lo anteriormente expuesto, la Corte considera que el procedimiento legal de reivindicación de tierras instaurado por los miembros de la Comunidad Sawhoyamaxa desconoció el principio del plazo razonable y se mostró completamente inefectivo, todo ello en violación de los artículos 8 y 25 de la Convención Americana, en concordancia con los artículos 1.1 y 2 de la misma...". 
sobre cuestiones que exceden el mero trámite que violentan derechos y garantías constitucionales de los imputados.

En la audiencia del 6-10-2020 con dicho objeto la defensa ofreció el informe de la Dra. Briones cuyos sólidos fundamentos persuadieron al Juez de Garantías Sergio Pichetto de hacer lugar a la participación del intérprete en Mapuzungun como un derecho de los imputados a hablar en su propio idioma, aunque no garantizó que el estado lo provea ni gestione ni abone gastos u honorarios, imponiéndoles dicha carga a los imputados solicitantes.

Así, en la audiencia en la cual se logró que la Fiscalía adhiriese a la solicitud de sobreseimiento de la defensa y se dejase sin efecto la medida cautelar de desalojo de la Comunidad intervino el Pu Kimche Leónidas Loncón quien interpretó al Lonko Mauro Millán en sus intervenciones en la audiencia.

\section{Conclusiones}

Los Pueblos indígenas tienen derecho al uso del propio idioma con apoyo en un sólido entramado de derecho positivo de raigambre constitucional y del derecho internacional de derechos humanos. Tanto la antropología como las ciencias jurídicas aporta razones para obligar a que los estados garanticen el uso del propio idioma a los pueblos indígenas procedimientos administrativos y judiciales: desde considerar las lenguas de los pueblos indígenas argentinos como idioma oficial como garantizar la intervención de intérpretes.

A la fecha, urge reformar el poder judicial cuya inadecuación en la mayoría de los sistemas judiciales argentinos generan obstáculos culturales que obligan a los indígenas, como sujetos vulnerables, a tener que litigar poder ejercer ese derecho humano fundamental de expresarse libremente en sede judicial en condiciones de igualdad.

Mientras ello no ocurra las deficiencias en la educación jurídica básica de los jueces, sus carencias de formación profesional 
y el racismo endémico del sistema judicial que desconoce los elementos básicos del derecho de los pueblos indígenas seguirán exigiendo que los litigantes manifiesten en su primera intervención su intención de usar su propio idioma y pidan -por medio de sus defensores- al estado que provea intérpretes en la lengua indígena en cuestión.

No expresarlo expone a los litigantes al riesgo de las interpretaciones monoculturales, racistas, dislógicas y restrictivas como hemos visto en el caso "Buenuleo" donde según las cuales al no expresarla en la primera actuación los indígenas no hay una "necesidad" de proveer intérpretes porque los imputados pueden expresarse y comprender el idioma oficial, lo que implica una violación al derecho y a la garantía que obliga al litigante indígena a desarrollar vías de impugnación para estar en condiciones de igualdad cultural en el proceso.

La experiencia de los casos estudiados, exigen asimismo que los litigantes exijan el intérprete como garantía del debido proceso legal donde la publicidad y la oralidad no pueden ser satisfechas sin la participación del pueblo indígena en el proceso en condiciones de igualdad de libre expresión en su propio idioma.

La denegación del intérprete conlleva los gravámenes tales como la lesión a la defensa en juicio contra quien ha visto afectado su derecho a ser oído en el proceso y participar en él condiciones de igualdad por no poder expresarse en su propio idioma que el pueblo bien puede considerar idioma oficial.

Así, excede completamente al debate y resulta irrelevante la comprensión o no del idioma castellano, ya que el uso del idioma indígena -en los ejemplos, el Mapuzungun- en las audiencias hace al derecho al debido proceso que exige como requisito de su legalidad que, cuando el imputado quiere usar su idioma y así lo pide, el estado provea un intérprete mapuzungun. En efecto, un requisito para legalidad del proceso: ser oído en su idioma, en su propia cultura, integra la garantía de la defensa en juicio de la persona tanto como la efectiva defensa técnica, 
comprenda o no el idioma dominante porque el derecho al idioma y al intérprete no se trata de un déficit en la capacidad cognitiva sino como un derecho humano fundamental de la persona y una garantía de publicidad y participación para el Pueblo indígena Mapuche del cual ella es integrante.

Recuperando la idea inicial: el derecho al uso del propio idioma de los pueblos indígenas en sede judicial interpela y pone al desnudo las ideas de supremacistas culturales que desprecian el derecho de los pueblos indígenas negándoles la libertad de expresarse en su idioma en los estrados judiciales. Lograr la efectiva garantía del intérprete para el uso del propio idioma indígena abre a los pueblos el desafío con un destino aún incierto, que exigir a los estados nacional y provincial tomar medidas positivas para su adecuación. Mientras tanto los avances dependerán, en buena medida, de la perseverancia e insistencia de los pueblos indígenas en sus planteos para lograr avances en cada estrado judicial, abriéndose paso entre el pensamiento dislógico, acrónico y racista arraigado en gran parte de los operadores judiciales. 